support with an extracorporeal temporary device may be appropriate.

\section{References}

1. Milano CA, Simeone AA. Mechanical circulatory support: devices, outcomes and complications. Heart Fail Rev. 2013;18:35-53.
2. Stulak JM, Cowger J, Haft JW, Romano MA, Aaronson KD, Pagani FD Device exchange after primary left ventricular assist device implantation indications and outcomes. Ann Thorac Surg. 2013;95:1262-7; discussion 1267-8.

3. Rogers JG, Bostic RR, Tong KB, Adamson R, Russo M, Slaughter MS. Cost-effectiveness analysis of continuous-flow left ventricular assist devices as destination therapy. Circ Heart Fail. 2012;5:10-6.

\title{
Recurrent esophagopericardial fistula in a patient with human immunodeficiency virus
}

\author{
Lloyd M. Felmly, BS, Walter F. DeNino, MD, and Chadrick E. Denlinger, MD, Charleston, SC
}

Esophagopericardial fistulas are rarely reported but carry a high mortality. They can arise from a variety of conditions, but most $(75 \%)$ have a benign etiology. ${ }^{1}$ Candida esophagitis is known to cause complications such as stricture, hemorrhage, and tracheoesophageal fistula. ${ }^{2}$ We present a case of esophagopericardial fistula associated with Candida esophagitis in a patient with advanced human immunodeficiency virus (HIV) infection.

\section{CLINICAL SUMMARY}

A 37-year-old man with a history of HIV infection and noncompliance with antiretroviral medications reported

From the Division of Cardiothoracic Surgery, Medical University of South Carolina, Charleston, SC.

Disclosures: Authors have nothing to disclose with regard to commercial support. Received for publication Oct 23, 2013; revisions received Dec 8, 2013; accepted for publication Dec 13, 2013; available ahead of print Feb 7, 2014.

Address for reprints: Chadrick E. Denlinger, MD, 25 Courtenay Dr ART Suite 7018, Charleston, SC 29425 (E-mail: denlinge@musc.edu)

J Thorac Cardiovasc Surg 2014;147:e48-9

$0022-5223 / \$ 36.00$

Copyright (c) 2014 by The American Association for Thoracic Surgery

http://dx.doi.org/10.1016/j.jtcvs.2013.12.057 chest pain and nausea. His CD4 count was 43 cells $/ \mathrm{mm}^{3}$, and the viral load was 17,000 copies $/ \mathrm{mL}$. An electrocardiogram showed diffuse ST-segment elevation, consistent with pericarditis. An esophagogram revealed a large communication between the esophagus and pericardium (Figure 1). A chest radiograph showed a pneumopericardium (Figure 2). Esophagogastroduodenoscopy 2 weeks previously had shown only esophagitis, without evidence of a stricture.

Because of the uncertainty of the fistula's location, a right thoracotomy was performed. The pericardium was opened, and $500 \mathrm{~mL}$ of purulent fluid was drained. Cultures later grew Candida krusei and $\alpha$-hemolytic Streptococcus species. Further inspection revealed a $3-\mathrm{cm}$ opening on the posterolateral wall of the esophagus near the gastroesophageal junction. The esophagus was closed around an $18 \mathrm{~F}$ biliary T-tube with the side arm exiting through the perforation and advanced inside a $28 \mathrm{~F}$ chest tube. Additional drains were placed in the pericardium and pleural space; no attempt was made to close the pericardium. Gastrostomy and jejunostomy tubes were placed.
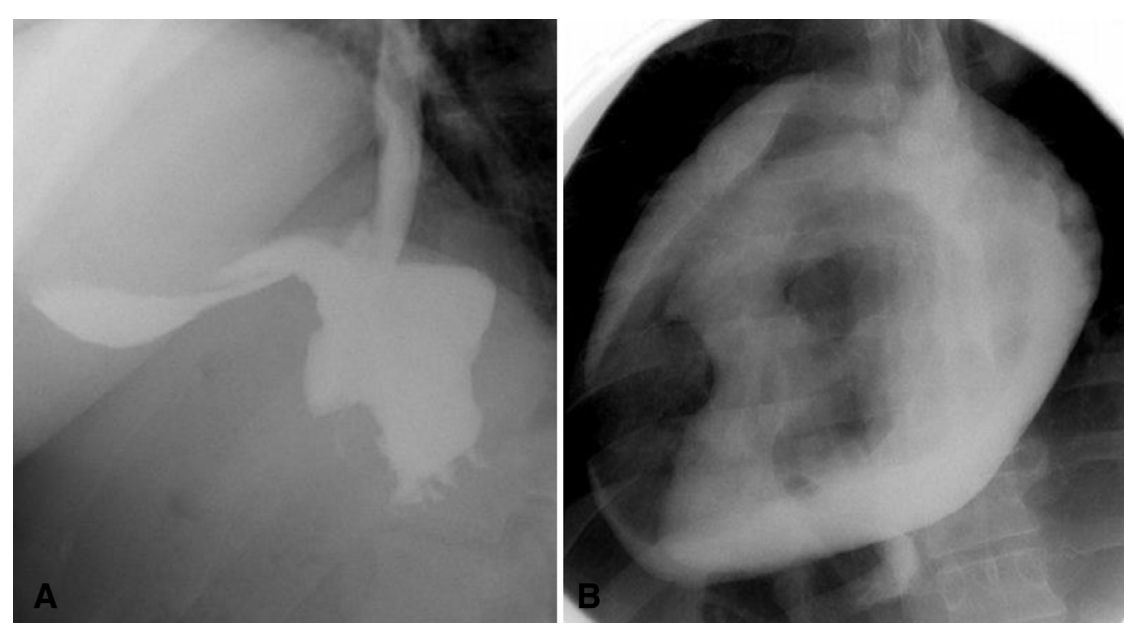

FIGURE 1. The diagnostic esophagogram showed contrast extravasation from the distal esophagus (A), which quickly filled the pericardial sac (B). 


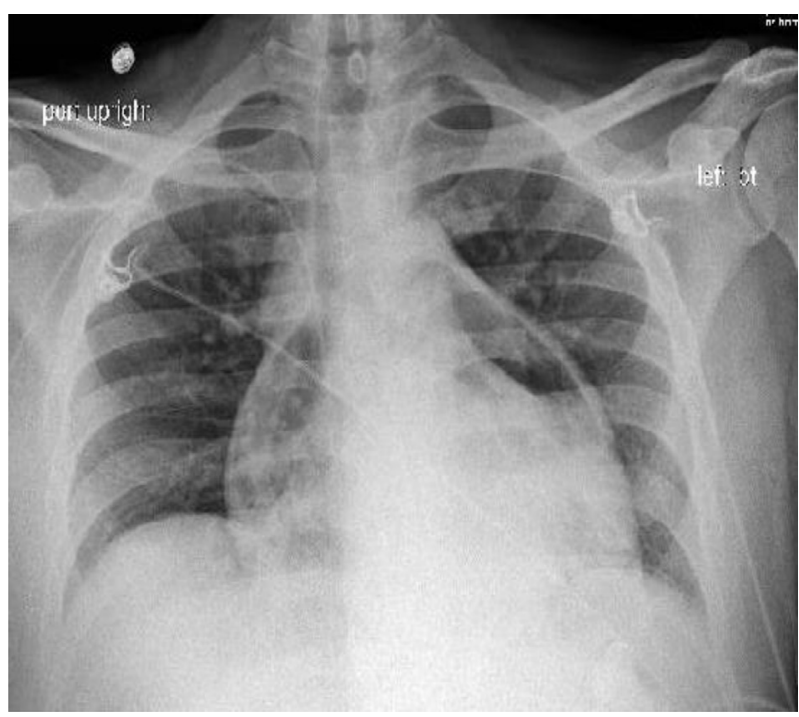

FIGURE 2. The preoperative chest radiograph demonstrated a significant pneumopericardium.

The patient's postoperative course was uncomplicated. Oral intake continued to be withheld, and jejunostomy tube feedings were initiated. Appropriate antiretroviral medications and antibiotics were started, and the patient was discharged 15 days after fistula closure. The T-tube was removed endoscopically 6 weeks after discharge. An esophagogram 3 days after T-tube removal revealed a small, persistent leak from the former T-tube site but no stricture or other abnormality. He was then discharged on complete nutritional support through the jejunostomy tube.

Two months after T-tube removal, the patient presented with a recurrent fistula and was returned to the operating room for a left thoracotomy and replacement of esophageal T-tube. A new 3-cm rent in the anterior aspect of the esophagus was situated $6 \mathrm{~cm}$ above the gastroesophageal junction and communicated with the pericardium. The sepsis was drained, and the defect was repaired as previously. The patient's postoperative course was complicated by persistent fevers, intolerance of enteric feeding, diarrhea, severe malnutrition, and malaise. Of note, throughout the course of treatment, the CD4 count never exceeded 76 cells $/ \mathrm{mm}^{3}$. Goals of care were discussed, and comfort care was initiated.

\section{DISCUSSION}

This case highlights the difficulties in treating esophagopericardial fistulas in the setting of advanced HIV infection. An esophagopericardial fistula is a rare condition that can arise as a complication of ulcerative esophagitis, malignancy, foreign-body ingestion, and iatrogenic causes such as bougienage, esophagogastroduodenoscopy, and radiofrequency ablation. To our knowledge, an esophagopericardial fistula has not previously been reported in association with HIV infection. There are a limited number of esophageal perforations associated with HIV in the literature. These perforations are typically associated with esophageal infections related to Candida, herpes simplex virus, or cytomegalovirus. Among these infections, Candida appears to be the pathogen most closely linked to perforations.

There are scant data to direct the ideal treatment of esophagopericardial fistulas, and the therapeutic decisions were based on experience with esophageal perforations with delayed diagnoses. Several treatment options for this condition exist. Endoscopic stenting can be used effectively for early treatment of focal insults, such as fistulas induced by radiofrequency ablation. ${ }^{3}$ Stent placement is not sufficient in the setting of large extraluminal fluid collections, in this case pericardial fluid, because of the need for drainage of the current sepsis.

Historically, delayed esophageal perforations have been managed with diversion. In this case, however, that option was declined because of our concern for the subsequent reconstruction. An alternative strategy, selected in this case, was to establish a controlled fistula by placing an esophageal T-tube with the side arm exiting through the perforation and into a chest tube. After the fistula matures, the T-tube is removed endoscopically while the chest tube remains fixated adjacent to the perforation. The chest tube is subsequently withdrawn slowly. A recent meta-analysis indicated that T-tube repairs were associated with higher mortality than were primary repairs, but this is likely related to selection bias. ${ }^{4}$ In contrast, Linden and colleagues ${ }^{5}$ reported that T-tube repairs, performed in a delayed fashion, showed no significant difference in mortality from earlier primary repairs. In summary, although different options exist for management of esophageal perforations, including ones that fistulize to the pericardium, diversion may provide the best outcomes for patients with severe malnourishment or immunologic suppression.

\section{References}

1. Miller WL, Osborn MJ, Sinak LJ, Westbrook BM. Pyopneumopericardium attributed to an esophagopericardial fistula: a report of a survivor and a review of the literature. Mayo Clin Proc. 1991;66:1041-5

2. Asayama N, Nagata N, Shimbo T, Nishimura S, Igari T, Akiyama J, et al. Relationship between clinical factors and severity of esophageal candidiasis according to Kodsi's classification. Dis Esophagus. July 4, 2013 [Epub ahead of print].

3. Eitel C, Rolf S, Zachäus M, John S, Sommer P, Bollmann A, et al. Successful nonsurgical treatment of esophagopericardial fistulas after atrial fibrillation catheter ablation: a case series. Circ Arrhythm Electrophysiol. 2013;6:675-81.

4. Biancari F, D'Andrea V, Paone R, Di Marco C, Savino G, Koivukangas V, et al Current treatment and outcome of esophageal perforations in adults: systematic review and meta-analysis of 75 studies. World J Surg. 2013;37:1051-9.

5. Linden PA, Bueno R, Mentzer SJ, Zellos L, Lebenthal A, Colson YL, et al. Modified T-tube repair of delayed esophageal perforation results in a low mortality rate similar to that seen with acute perforations. Ann Thorac Surg. 2007;83:1129-33. 